\title{
Design and Implementation of a PLM System for Sustainable Manufacturing
}

\author{
Wen-Bin Zhao, Yang Ho Park, Hye Yun Lee, Chan Mo Jun, and Sang Do Noh* \\ Dept. of Systems Management Engineering, SungKyunKwan University \\ 300 Cheoncheon-dong, Suwon, Gyeonggi-do, 400-746 Korea \\ sdnoh@skku.edu
}

\begin{abstract}
Since the beginning of the industrial revolution, manufacturing industries have primarily been responsible for adverse effects on the environment caused by pollutants such as carbon dioxide. Therefore, there has been tremendous pressure for these industries to be globally competitive within the range of environmental regulations and laws, which has been greatly increased and reinforced these days. In addition, manufacturing industries have been confronted with new challenges owing to the depletion of energy and natural resources, economic stagnation, and increasing human needs that become very diverse. Thus, low-carbon green growth, cleaner production, and eco-friendly products are main issues, and sustainable manufacturing is the driving direction in the future manufacturing industry.

PLM (Product Lifecycle Management) is one of the innovative manufacturing paradigms that leverage e-business technologies in order to allow a company's product content to be developed and integrated with all company business processes through an extended enterprise. In this paper, we designed a new information model and a PLM system for sustainable manufacturing using UML methodology. We performed thoughtful analyses of existing PLM and sustainable indicator, basic schema and information model for supporting sustainable manufacturing engineering are developed. This paper also presents apractical case study showing information model and sustainable engineering by using commercial PDM software.
\end{abstract}

Keywords: PLM(Product Lifecycle Management), Sustainable Manufacturing, Information Model, UML(Unified Modeling Language).

\section{Introductions}

A study released by the U.S. National Academy of Sciences (NAS) in 2010 said, "Climate change is occurring, is caused largely by human activities, and poses significant risks for - and in many cases is already affecting - a broad range of human and natural systems."[1].Since the beginning of the industrial revolution, manufacturing industries have primarily been responsible for adverse effects on the environment caused by pollutants such as carbon dioxide. Therefore, there has been tremendous

\footnotetext{
* Corresponding author.
} 
pressure for these industries to be globally competitive within the range of environmental regulations and laws, which has been greatly increased and reinforced these days. In addition, manufacturing industries have been confronted with new challenges owing to the depletion of energy and natural resources, economic stagnation, and increasing human needs that become very diverse. Thus, low-carbon green growth, cleaner production, and eco-friendly products are main issues, and sustainable manufacturing is the driving direction in the future manufacturing industry.

Sustainable manufacturing is a new paradigm in which manufacturing industries produce their products in a sustainable manner to maintain global competitiveness while coping with recent challenges and problems. According to the report by the Brundtland Commission in 1987, sustainable development is defined as "development that meets the needs of the present without compromising the ability of future generations to meet their own need." This description has generally been quoted as the definition that best expresses the concept of sustainability[2].

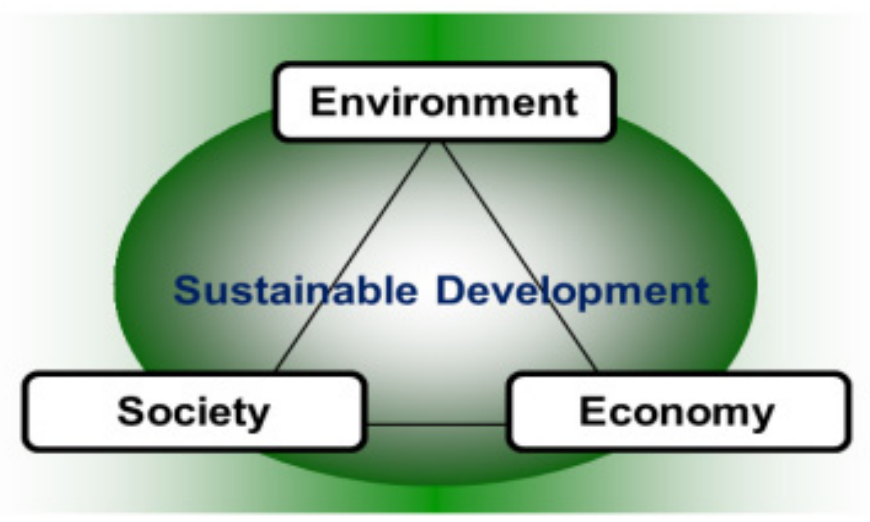

Fig. 1. Concepts of sustainable development

As shown in Figure 1, sustainable development is balanced development satisfying economic and social development as well as protecting environments [3,4]. The goal of sustainable development is to "meet the needs of the present without compromising the ability of future generations to meet their own needs." As key forces in society, organizations of all kinds have an important role to play in achieving this goal[5].Sustainable development as a manufacturing industry requires new and innovative choices and ways of thinking as well as the production of sustainable products such as energy efficiency and green growth[4,6]. Knowledge and technological advancement lead to economic growth in addition to resolving factors threatening the relationship between our social relations and manufacturing industries as well as environmental and economic sustainability.Therefore the PLM philosophy that is utilized broadly in manufacturing industry also has to have contribution to the sustainable development in engineering activity. 
In this research, we designed a new information model and a PLM system for sustainable manufacturing using UML methodology. We performed thoughtful analyses of existing PLM and sustainable indicator, basic schema and information model for supporting sustainable manufacturing engineering were developed. This paper also presents detailed case studyfor sustainable PLM using commercial PDM software.

\section{Backgrounds}

\subsection{UML(Unified Modeling Language) Methodology}

UML(Unified Modeling Language) is a standardized general-purpose modeling language in the field of object-oriented software engineering. The standard is managed, and was created, by the Object Management Group. It was first added to the list of OMG adopted technologies in 1997, and has since become the industry standard for modeling software-intensive systems[7]. And, UML is used to specify, visualize, modify, construct and document the artifacts of an object-oriented software-intensive system under development.

UML combines techniques from data modeling (entity relationship diagrams), business modeling (work flows), object modeling, and component modeling. It can be used with all processes, throughout the software development life cycle, and across different implementation technologies[7]. UML has synthesized the notations of the Booch method, the Object-modeling technique (OMT) and Object-oriented software engineering (OOSE) by fusing them into a single, common and widely usable modeling language. UML aims to be a standard modeling language which can model concurrent and distributed systems. UML is a de facto industry standard, and is evolving under the auspices of the Object Management Group (OMG).The UML methodology is largely divided into the structural model, behavior model and architectural model. This research used the structural model of systems designing the information model primarily as Class Diagram and Case Diagram[8,9].

\subsection{Existing PLM Information Model}

For the past several years, a considerable number of PLM systems have been designed and established in order to perform engineering in manufacturing industries. Among them, there is the PLM system composed of the P3R information model dividing PLM information into P3R(Product, Process, Plant and Resource) to promote production improvement.

In this paper, a P3R information modelwhich was introduced in the book of "Digital Factory for Human-oriented Production System”, is referenced as existing PLM information model [10]. As shown in Figure2, it is managed primarily in the unit of process and substructures such as products produced in this process, resources used in the process and plant information belongs to this process. 


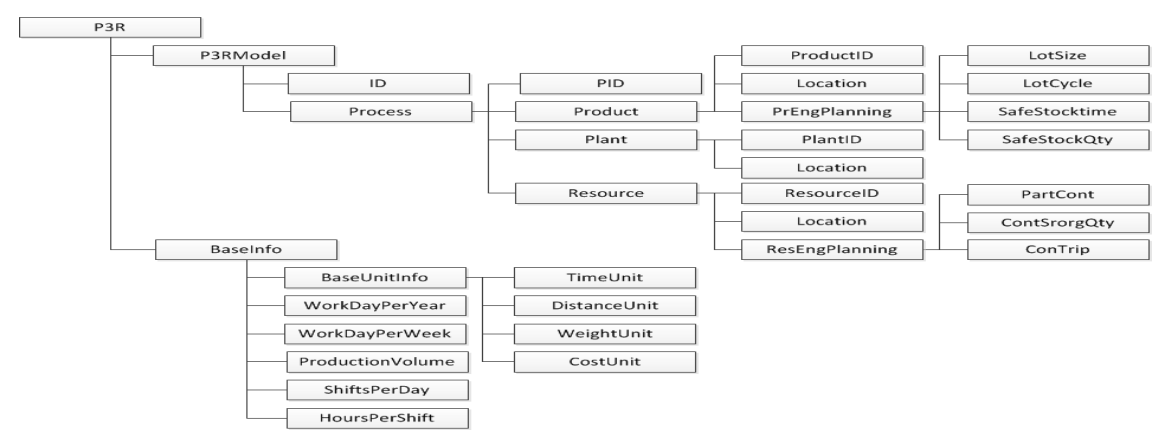

Fig. 2. An existing PLM information model [10]

\section{Sustainability Indicator}

\subsection{GRI(Global Reporting Initiative) Sustainability Indicator}

In 1997, the United Nations Environment Programme(UNEP) together with the United States nongovernmental organization, Coalition for Environmentally Responsible Economics(CERES) launched the GRI with the goal of "enhancing the quality, rigour and utility of sustainability reporting"[5]. Reporting is therefore the strong focal point of the guidelines. The GRI uses a hierarchical framework in three focus areas, namely social, economic, and environmental. The hierarchy consists of categories, aspects, and indicators. The guideline contains more than 100 indicators. However, not all the indicators are easy to evaluate and no guidance is given on how to choose between the indicators[11]. The guideline does, however, indicate what should be considered at a lower level, i.e. operational or project level within the company, especially if the company reports on sustainability using the GRI principles[12].

\subsection{IChemE Sustainability Indicator}

The Institution of Chemical Engineers (IChemE) published a set of sustainability indicators in 2002 to measure the sustainability of operations within the process industry. The IChemE provides standard reporting forms and conversion tables[13]. This framework is less complex and impact-oriented. However, the framework strongly favors environmental aspects, as well as quantifiable indicators that may not be practical in all operational practices, e.g. in the early phases of a project's life cycle[14].

\subsection{Sustainability Indicatorsfor Sustainable PLM}

Elements associated with sustainable development were organized based on GRI reports as well as additional supplementary IChemE reports[15]. As shown in Figure 3, this paper defined sustainable development elements for Sustainable PLM and classified as environmental indicators, economic indicators, and social indicators. Environmental indicators are composed of materials used, energy, 
emissions/pollution, biodiversity and compliance; economic indicators are composed of investment, economic performance, market presence and indirect economic effect. Finally, social indicators are composed of labor practices, human rights, social influence and product responsibility.

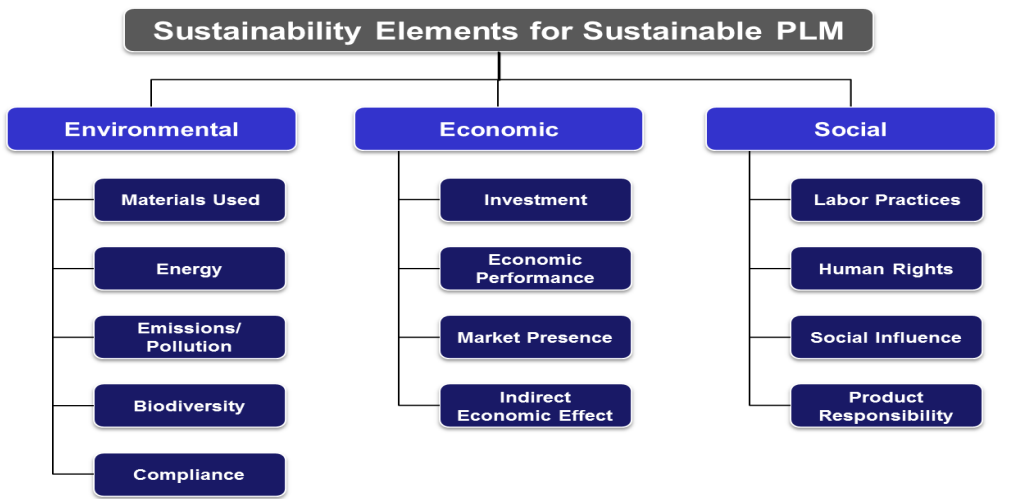

Fig. 3. Sustainability indicators for sustainable PLM

\section{$4 \quad$ PLM Information Model for Sustainable Manufacturing}

\subsection{Defines Use Case Actors}

This paper analyzed the requirements for Sustainable Engineering using the Use Case Diagram in order to classify elements of sustainable development by using the UML methodology. Actors performing acts in sustainable engineering systems were defined for the use of the Use Case Diagram. As in Figure 4, from the aspect of corporations, the actor is the company, from the social aspect, the actor is the customer and society, from a national aspect, the actor is the government, and from an environmental aspect the actor is Earth.
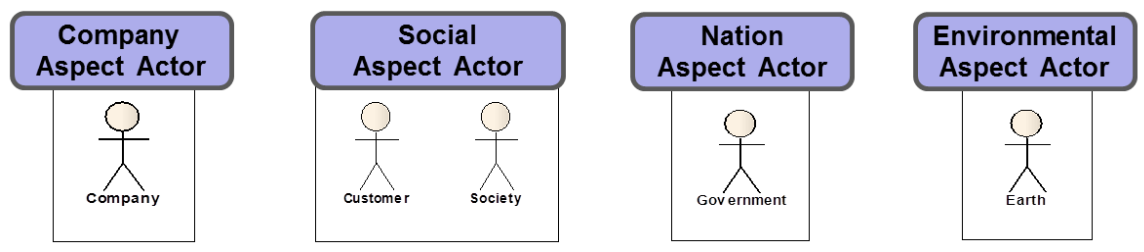

Fig. 4. Defines use case actors

\subsection{Defines Data Class}

Figure 5 shows the analysis and classification of requirements for elements of sustainable development by using the Use Case Diagram and Class Diagram. 


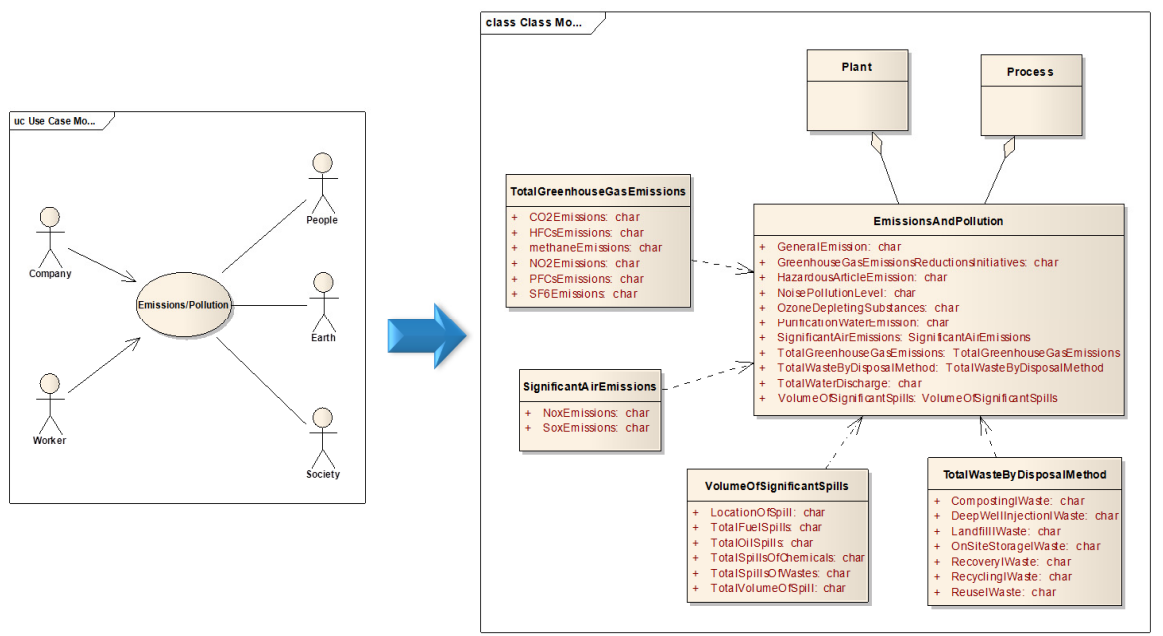

Fig. 5. Defines use case diagram and class diagram

\subsection{Sustainable PLM Information Model}

The final Sustainable PLM superordinate class was composed through an analysis of requirements and classification on elements of sustainable development for Sustainable PLM.As shown in Figure 6, the subordinate class is added for compliance as information composition for Product which is a Sustainable PLM information model superordinate class.

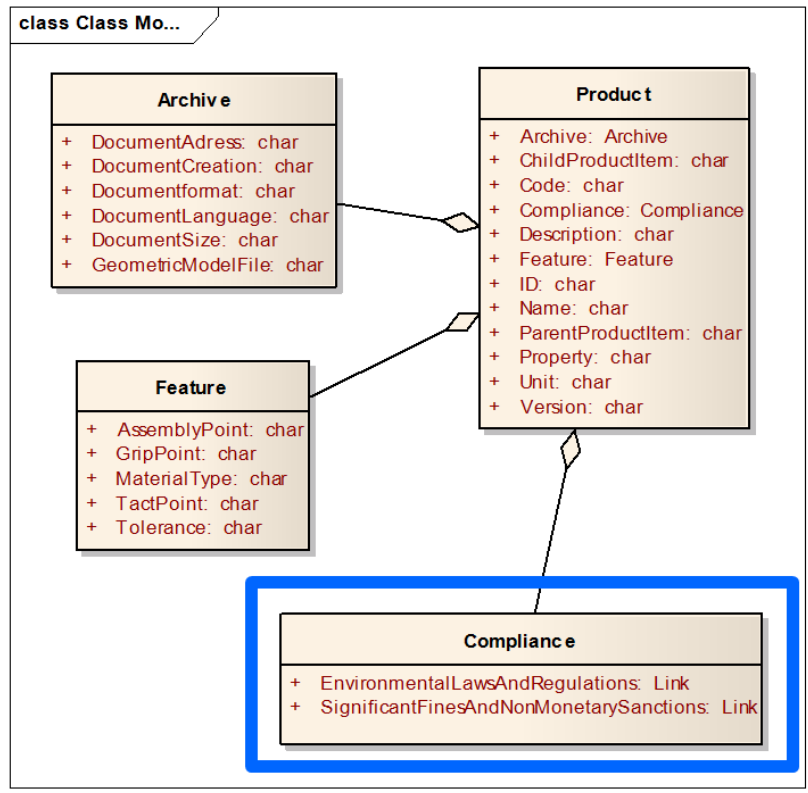

Fig. 6. Sustainable PLM information model (Product) 


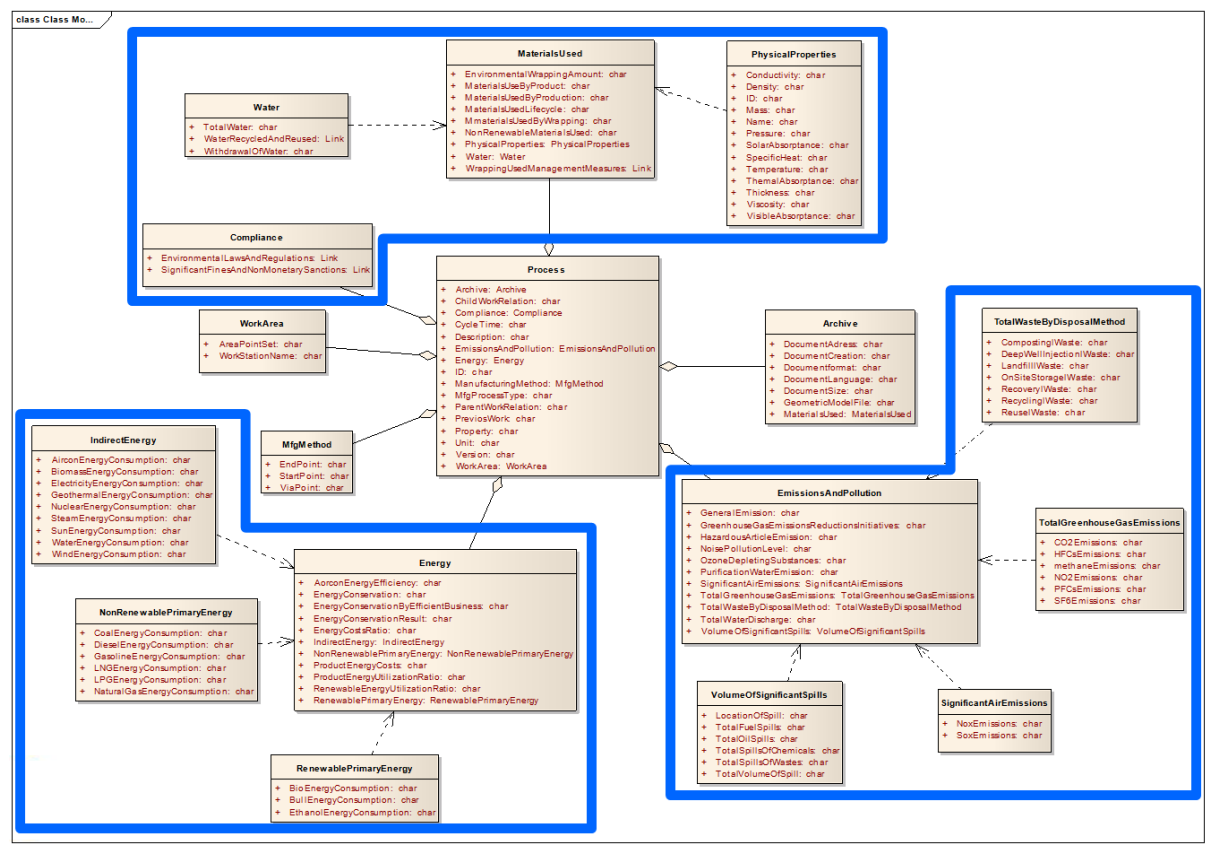

Fig. 7. Sustainable PLM information model (Process)

As in Figure 7, the subordinate class is added for compliance, used materials, energy and emissions/pollution as information composition for Process which is a Sustainable PLM information model superordinate class.

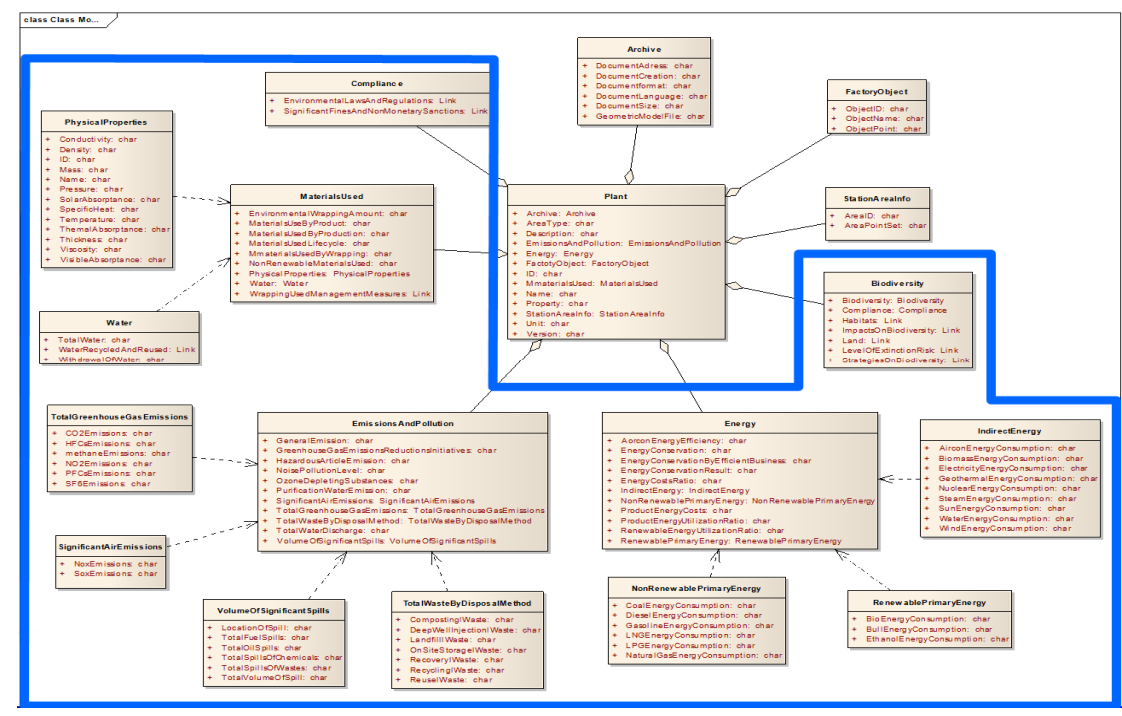

Fig. 8. Sustainable PLM information model (Plant) 
As shown in Figure 8, the subordinate class is added for compliance, materials used, biodiversity, energy and emissions/pollution as information composition for Plant which is a Sustainable PLM information model superordinate class.

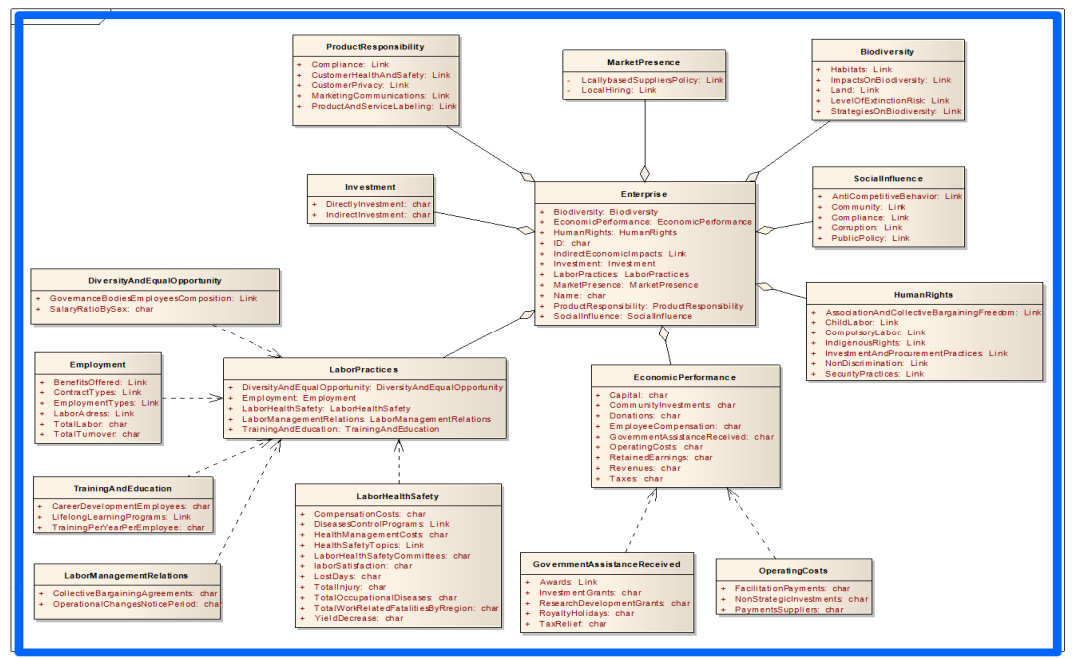

Fig. 9. Sustainable PLM information model (Enterprise)

As shown in Figure 9, the Enterprise model is shown as the superordinate class of the newly added Sustainable PLM information model. Elements of sustainable cannot be contained in the P3R model leading to the need for data management with the Enterprise class from the corporate aspect. The superordinate class Enterprise which was added is composed of investment, economic performance, indirect economic effect, market presence, social influence, product responsibility, labor practices and human rights as the subordinate class.

Existing PLM

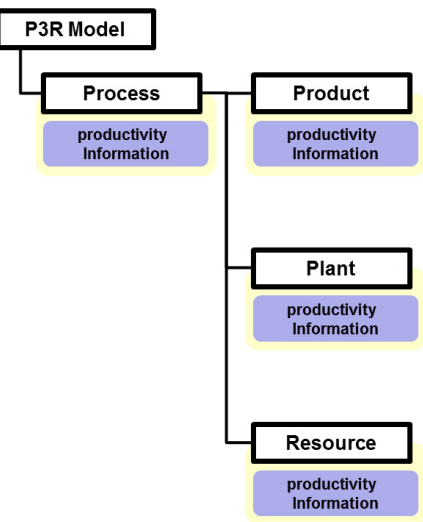

Sustainable PLM

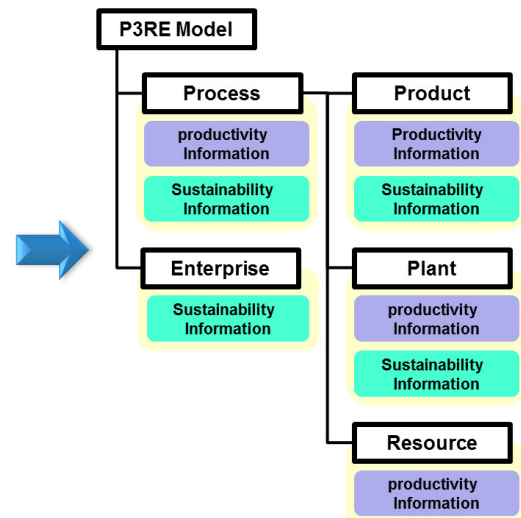

Fig. 10. Sustainable PLM information model 
Figure 10 is showing the comparison between construction of existing PLM information model and the construction of sustainable PLM information model. The existing PLM information model as the Process unit is composed of Product information and Plant information which is the affiliated plant, Resource information which is the used facility and Product information which is the produced product. However, all the information is information that is managed in order to improve productivity. Sustainable PLM information model has Enterprise information of the affiliated corporation which is the superordinate class and additionally managed information associated with sustainability in Plant information, Product information, and Process information.

\section{$5 \quad$ Implementations and a Case Study}

This paper, in order to verify Sustainable PLM information model collected related data based on the TOTAL basic application case which is the typical LCA Software. As shown in Figure 11, this case after passing through a total of 9 processes by using 12 kinds of materials, 9 resources and 5 kinds of energy emits 9kinds of product/part, 5 kinds of emissions and 5 kinds of pollutant.

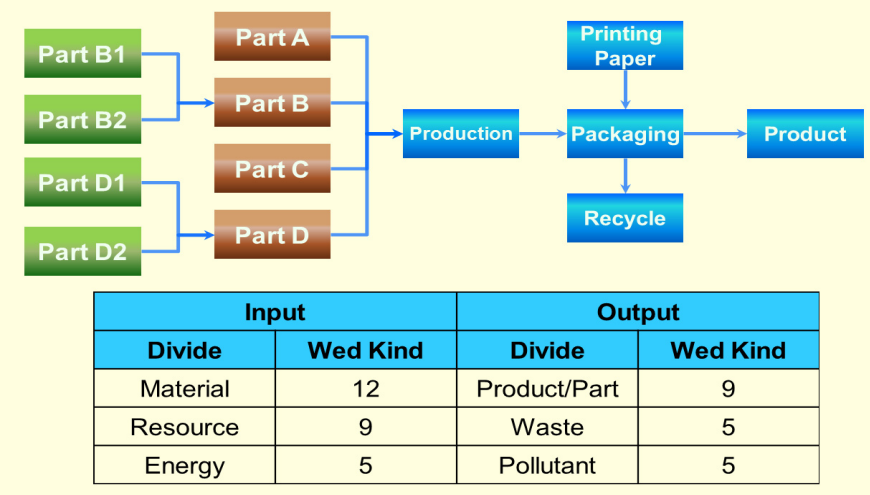

Fig. 11. General information of a case study

As shown in Figure 12 and 13, the effectiveness of the Sustainable PLM information model is being verified since all related data is managed and expressed through the applicable class of the proposed Sustainable PLM model. 


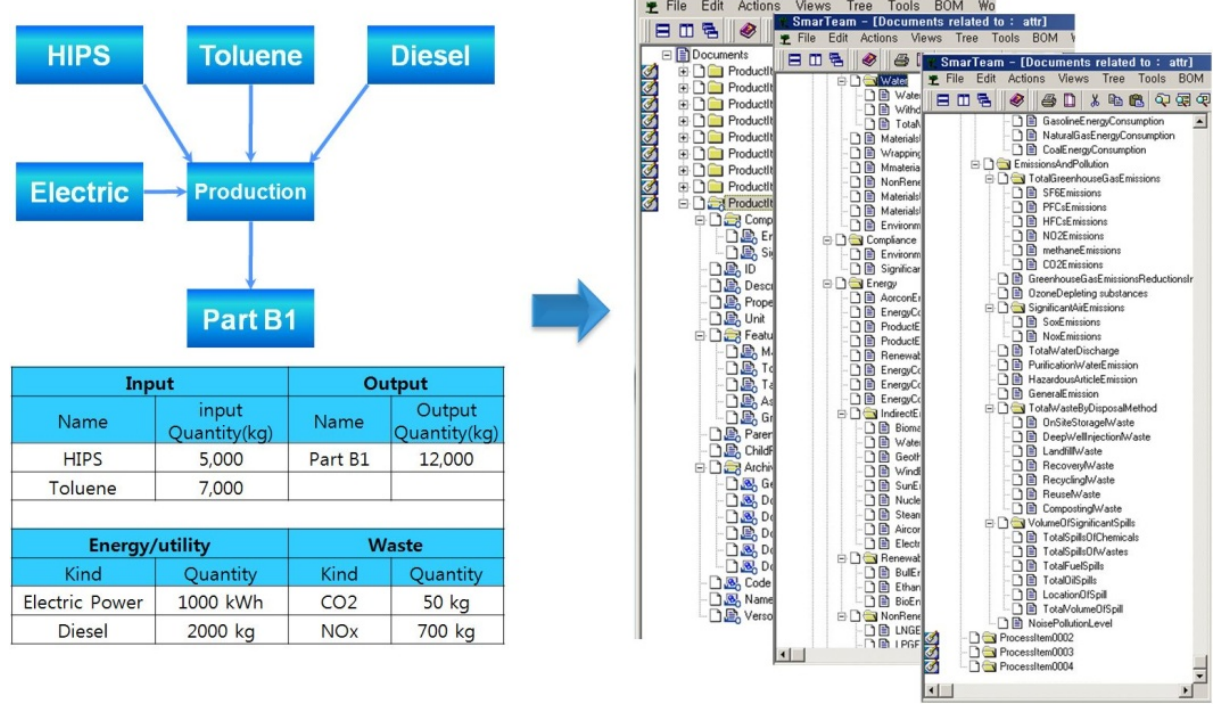

Fig. 12. Implementations for a case study

\begin{tabular}{|c|c|c|c|}
\hline \multicolumn{2}{|r|}{ Divide } & Wed Kind & PackingUsedClass \\
\hline \multirow{3}{*}{$\begin{array}{l}\bar{z} \\
\stackrel{0}{\risingdotseq}\end{array}$} & Material & 12 & ResourceClass \\
\hline & Resource & 9 & RenewablePrimaryEnergyClass \\
\hline & Energy & 5 & NonRenewablePrimaryEnergyClass \\
\hline \multirow{3}{*}{ 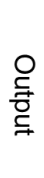 } & Product/Part & 9 & IndirectEnergyClass \\
\hline & Waste & 5 & ProductClass \\
\hline & Pollutant & 5 & TotalWasteByDisposalMethodClass \\
\hline & & & HazardousArticleEmissionClass \\
\hline
\end{tabular}

Fig. 13. Results of implementations for a case study

\section{Conclusions}

This paper has designed the new product life cycle management information model in order to support sustainable engineering in the manufacturing industry. First, an analysis on studies related to sustainable energy and national standard sustainable development reports and sustainability achievement indicators were established. Moreover, the PLM information model was designed for a new Sustainable Engineering based 
on the existing PLM information model as well as classification of sustainability elements through UML methodology.

The information model that is proposed in this paper has to be detailed and simplified for future utilization, and it is needed to construct an integrated system that is able to conduct analysis on both productivity and sustainability simultaneously.

Acknowledgment. This research was supported by a grant (Program No.: C6A2402) from BK21 Research \& HRD Group for Management of Complex Systems. This support is gratefully acknowledged.

\section{References}

1. National Academy of Sciences. Advancing the Science of Climate Change (2010), http: / /www . nap. edu / (accessed June 21, 2011)

2. Lee, J.Y.: MAS2: Modeling \& Simulation-based Life Cycle Evaluation for Sustainable Manufacturing, Ph.D. Thesis, Sungkyunkwan University, Suwon, Korea (2011)

3. Forestry Commission of Great Britain. Sustainability (2011), http://www . forestry.gov.uk/ (accessed March 7, 2011)

4. National Council for Advanced Manufacturing, Sustainable Manufacturing (2011), http: / / www . nacfam.org/ (accessed December 11, 2010)

5. Global Reporting Initiative, Sustainability Reporting Guidelines, ver. 3.1 (2011), http: / /www.globalreporting.org/ (accessed June 2, 2011)

6. Jayal, A.D., Badurdeen, F., Dillon Jr., O.W., Jawahir, I.S.: Sustainable manufacturing: Modeling and optimization challenges at the product, process and system levels. CIRP Journal of Manufacturing Science and Technology 2(3), 144-152 (2010)

7. Wikipedia, Unified Modeling Language (2011), http://en.wikipedia.org/ (accessed March 8, 2008)

8. Chun, B.S.: UML essence, Wowbooks, Seoul, Korea (2011)

9. Thimm, G., Lee, S.G., Ma, Y.S.: Towards unified modeling of product life-cycles. Computers in Industry 57(4), 331-341 (2006)

10. Canetta, L., Redaelli, C., Flores, M.: Digital Factory for Human-Oriented Production System, pp. 59-72. Springer (2011)

11. Veleva, V., Ellenbecker, M.: A proposal for measuring business sustainability: addressing shortcomings in existing frameworks. Greener Management International 31(3), 101-120 (2000)

12. Labuschagne, C., Brent, A.C., Erck van, R.P.G.: Assessing the sustainability performances of industries. Journal of Cleaner Production 13(4), 373-385 (2005)

13. IChemE, The sustainability metrics: sustainable development progress metrics recommended for use in the process industries. Institution of Chemical Engineers (2010), http: / / www. icheme.org/ (accessed May 24, 2011)

14. Labuschagne, C.: Sustainable project life cycle management: Criteria for the South African process industry, Master's Thesis, University of Pretoria (2003)

15. Zhao, W.B.: A study on concept design of a PLM system for sustainable engineering. In: Annual Conference of CAD/CAM, PyeongChang (2012) 